\title{
STROKE \\ CLINICAL PATTERNS OF STROKE IN LAHORE GENERAL HOSPITAL, A TERTIARY CARE CENTER
}

1. B.Sc, MBBS, FCPS (Medicine), MRCP (UK), MRCPS (Glasg) FRCP (Edin), FRCP (Glasg) Associate Professor Medicine Ammer ud Din Medical College Postgraduate Medical Institute, Lahore General Hospital Lahore.

2. Assistant Professor Medical 1

3. Pharm D, M Phil (Pharmacology) Punjab University College of Pharmacy,

4. Postgraduate Resident

\section{Correspondence Address:}

Dr. Muhammad Imran Hasan Khan Associate Professor Medicine Ammer ud Din Medical College

Postgraduate Medical Institute, Lahore General Hospital Lahore. mimranhkhan@hotmail.com

Article received on:

04/04/2016

Accepted for publication:

$15 / 05 / 2016$

Received after proof reading:

04/05/2016

\section{Dr. Muhammad Imran Hasan Khan ${ }^{1}$, Asim Hameed ${ }^{2}$, Zohaib Abbas Khan ${ }^{3}$, Sana Fatima ${ }^{4}$}

\begin{abstract}
Background: Stroke is a leading cause of disability and the second principal cause of death in the world. The aim of this study was to analyze different characteristics in stroke patients in Medical Unit 1 of Lahore General Hospital, which is biggest referral hospital for Neurology patients in Punjab, to identify the risk factors and help in targeting prevention in our patients. Study Design: Descriptive study. Setting: Lahore General Hospital, Lahore. Period: January 2016, including data from January to November 2015. Methods: The demographic data, clinical manifestations, risk factors, side of weakness, cranial nerves involved, neurological weakness and Glasgow Coma Scale, duration of stay in hospital and outcome were included in the data. For the comparison between categorical variables Chi-square test was used. For other variables, t-test was used. Results: A total of 235 patients with stroke, age 20 to 105 (mean $\pm \mathrm{SD}=58 \pm 14.6$ ) were included. $127(54 \%)$ had Ischemic stroke (IS) and $100(42.6 \%)$ had hemorrhagic stroke (HS). 127 (54\%) were men and 108 (46\%) were women. 17.9\% of the patients with IS and $21.7 \%$ of the patients with HS died (OR $0.6595 \% \mathrm{Cl} 0.48-0.89$ ). Hypertension, diabetes and dyslipidemia were the most common risk factors. Conclusion: Burden of stroke is high in Pakistan. Mean age of patients with stroke is less. Hypertension, diabetes, dyslipidemia and smoking are highly prevalent and hypertension is the most common. Ischemic strokes are more common, mortality of intra-cerebral hemorrhage is higher.
\end{abstract}

Key words: Stroke, Hypertension, Clinical patterns, Lahore

Article Citation: Khan MIH, Hameed A, Khan ZA, Fatima S. Clinical patterns of stroke in Lahore general hospital, a tertiary care center. Professional Med J 2016;23(5):539545. DOI: $10.17957 / T P M J / 16.3388$

\section{INTRODUCTION}

Stroke is defined as rapid progression of neurological symptoms which can be very restricted or may involve a larger area of the brain. It can result in a variable weakness, lasting few minutes to affecting rest of all life. When it effects for a shorter period, the recovery is usually better, but there is a likelihood of future attacks as all prerequisites are present. It is broadly divided into Ischemic Stroke (IS) and Hemorrhagic Stroke (HS). It is the major cause of disability and second major cause of death worldwide. ${ }^{1}$

It is reported in literature that stroke incidence is more common in female gender. A likely age for it is variable in different ethnic groups. It is most common in 15-45 years in men, however, seventh decade is the most common for occurrence. ${ }^{2}$ In our population, the incidence is either equal or may be slightly higher in men. In few studies it was documented that $26 \%$ and $34 \%$ of patients in our population was below 45 and 50 years of age respectively. ${ }^{3}{ }^{4}$ In another study, $28 \%$ of patients were under 55 years. The male to female ratio was documented at 1.5. ${ }^{5}$ These studies were different from our study in many respects. The inclusion criteria did not allow them to include younger age groups, which we are used to seeing in our institution. Our hospital is famous for the Neurosurgery and provides tertiary care for all patients in Punjab specially, and all across Pakistan otherwise.

There are different causes for stroke in different age groups. At a younger age, coronary artery disease is documented as a major contributor. ${ }^{6}$ 
with advancing age, the risk increases and doubles after the age of 55 years. ${ }^{1}$ The risk factors can be divided into modifiable and nonmodifiable. Age, sex and family history are taken as non- modifiable, whereas hypertension, diabetes, abnormal lipid profile, tobacco use, heart disease, increased salt intake, decreases physical activity, obesity and unhealthy diet are taken as modifiable risk factors. ${ }^{7}$ There are certain overlooked risk factors also present which include low socioeconomic status, mental ill health, psycho social stress, use of alcohol and certain medications, etc. ${ }^{8}$ There very little data available in our population in Pakistan, which will add to literature. Identification of these risk factors will help in further planning for risk reduction.

Different incidence is documented in literature for different countries. In the United States, 780,000 strokes occur each year, out of which $87 \%$ are IS \& $13 \%$ are $\mathrm{HS} .{ }^{9},{ }^{10} \mathrm{~A}$ recent community survey in Kolkata by the Indian Council of Medical Research, showed the average annual incidence of stroke as 145 per 100,000 persons per year. In China, it was 116 to 219 per 100,000 per year. ${ }^{11}$ Annual incidence in Pakistan is documented at $250 / 100,000$ cases every year, but this was a very old estimate. ${ }^{3}$ No large scale epidemiological studies are available from this region, so this study will contribute in estimation of incidence of stroke in Pakistan.

Each year, 55 million deaths occur worldwide, and $10 \%$ of them are due to the stroke. Stroke is the third most common cause of death, and the leading cause of disability all over the world. ${ }^{11}$ It was reported that patients with Intra Cerebral Hemorrhage, intra-ventricular extension, low GCS and systolic BP greater than $180 \mathrm{mmHg}$ predict in-patient mortality. As death due to stroke is increasing worldwide, we want to see the mortality rate and its preventable causes in our population as well. ${ }^{3}$

The rationale of our study was to analyze different characteristics of stroke patients of both sexes and age groups above 18 years admitting in Medical Unit 1 of Lahore General Hospital. We wanted to identify the risk factors and assess the effect of degree of conscious level on mortality. This can help us in targeting prevention in our patients.

\section{MATERIALS AND METHODS}

This Descriptive study was carried out in Lahore General Hospital, Lahore in January 2016, including data from January to November 2015. All patients admitted with stroke in Medical Unit 1 of Lahore General Hospital were included. The demographic data, clinical manifestations, risk factors, side of weakness, cranial nerves involved, neurological weakness and Glasgow Coma Scale, duration of stay in hospital and outcome were included in the data. Patients who did not had proven diagnosis of either ischemic or hemorrhagic stroke, were excluded from the study even if they were admitted in unconscious state. The confirmation of stroke was taken as imaging (magnetic resonance imaging (MRI) or computerized tomography scan (CT scan)).

SPSS software for Windows (version 21, SPSS Inc., Chicago, IL, USA) was used for the statistical analysis of the data. For the comparison between categorical variables Chi-square test was used. In case of normal variables, t-test was used. P < 0.050 was considered statistically significant.

\section{RESULTS}

In our study we included 235 patients, who were hospitalized. The age ranged between 20 and 105 (mean $\pm S D=58 \pm 14.6$ ). 25 patients (10.6\%) had age of 40 years or less. In these patients 125 (54\%) were men and 108 (46\%) were women. The age of most of the patients was between 40 to 60 years. 127 (54\%) had Ischemic stroke (IS) and 100 (42.6\%) had hemorrhagic stroke (HS). The mean age of the patients with IS was 59.4 \pm 15.6 and those with HS was $56.6 \pm 13.3$. Only 17 patients $(7.2 \%)$ had a recurrent stroke. There was no significant association between mortality and different age groups ( $p=0.46$ ) (Table: $I$ ). $42.6 \%$ of the patients died during their stay in the hospital. Most patients of less than 40 years died with first stroke. $17.9 \%$ of the patients with IS and $21.7 \%$ of the patients with HS died (OR $0.6595 \% \mathrm{Cl} 0.48-0.89$ ). Mortality rate was almost equal in both genders. 
$53(22.6 \%)$ males and 47 (20\%) females expired out of total of $235(p=0.93)$.

\begin{tabular}{|c|c|c|}
\hline Age Groups & Frequency (\%) & Mortality (\%) \\
\hline$<40$ & $25(10.6)$ & $14(56)$ \\
\hline $41-50$ & $62(26.4)$ & $22(35.5)$ \\
\hline $51-60$ & $54(23.1)$ & $20(37)$ \\
\hline $61-70$ & $49(20.9)$ & $23(46.9)$ \\
\hline $71-80$ & $33(14)$ & $16(48.5)$ \\
\hline$>80$ & $12(5.1)$ & $5(41.7)$ \\
\hline Total & $235(100)$ & $100(42.6)$ \\
\hline \multicolumn{2}{|c|}{ Table-l. Age groups and mortality rates } \\
\hline
\end{tabular}

Hypertension, Diabetes Mellitus, Smoking and obesity were the most common risk factors in these patients (Figure 1).

The prevalence of dyslipidemia, ischemic heart disease, hypertension and DM were significantly different between the different age groups. IHD, DM, Hypertension and dyslipidemia were more common in age group of $>40,51-60,61-70$ and more than 70 years respectively (Figure 2 ).

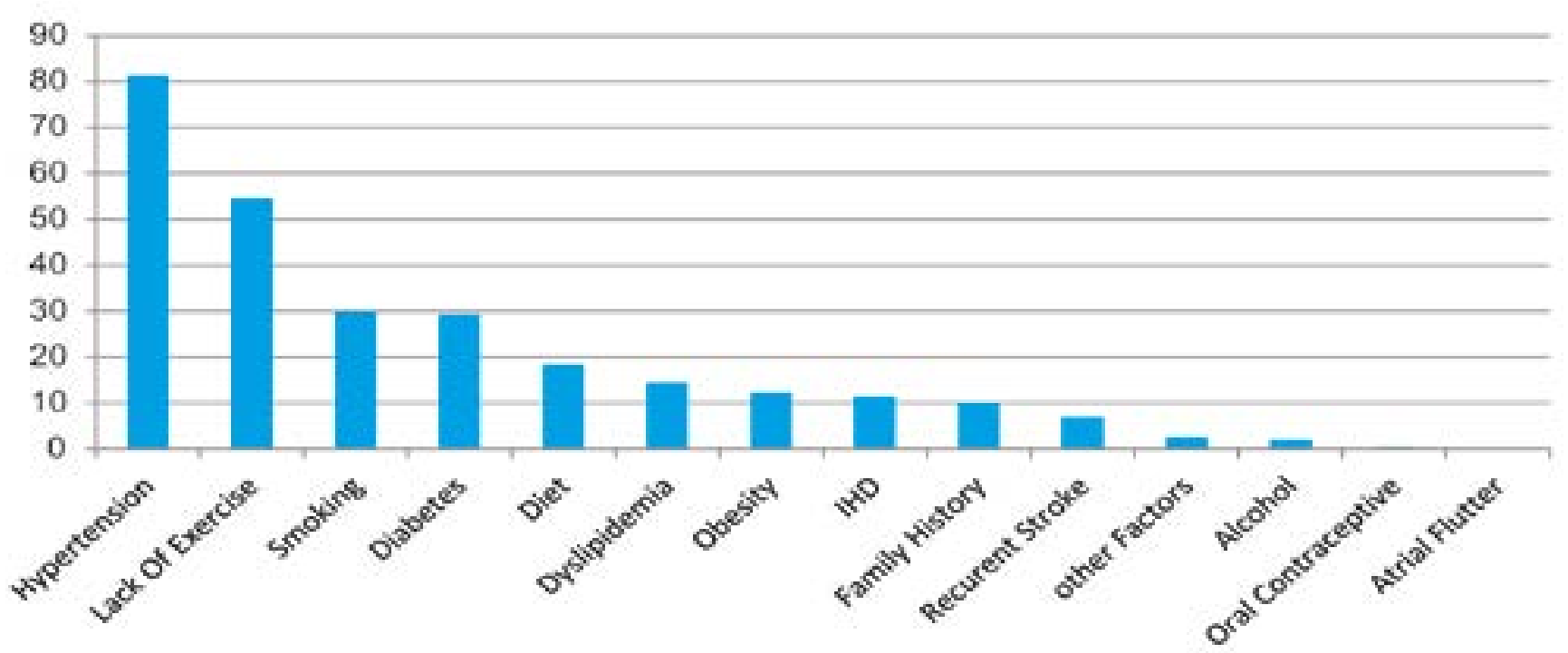

Figure-1. Risk factors with percentages

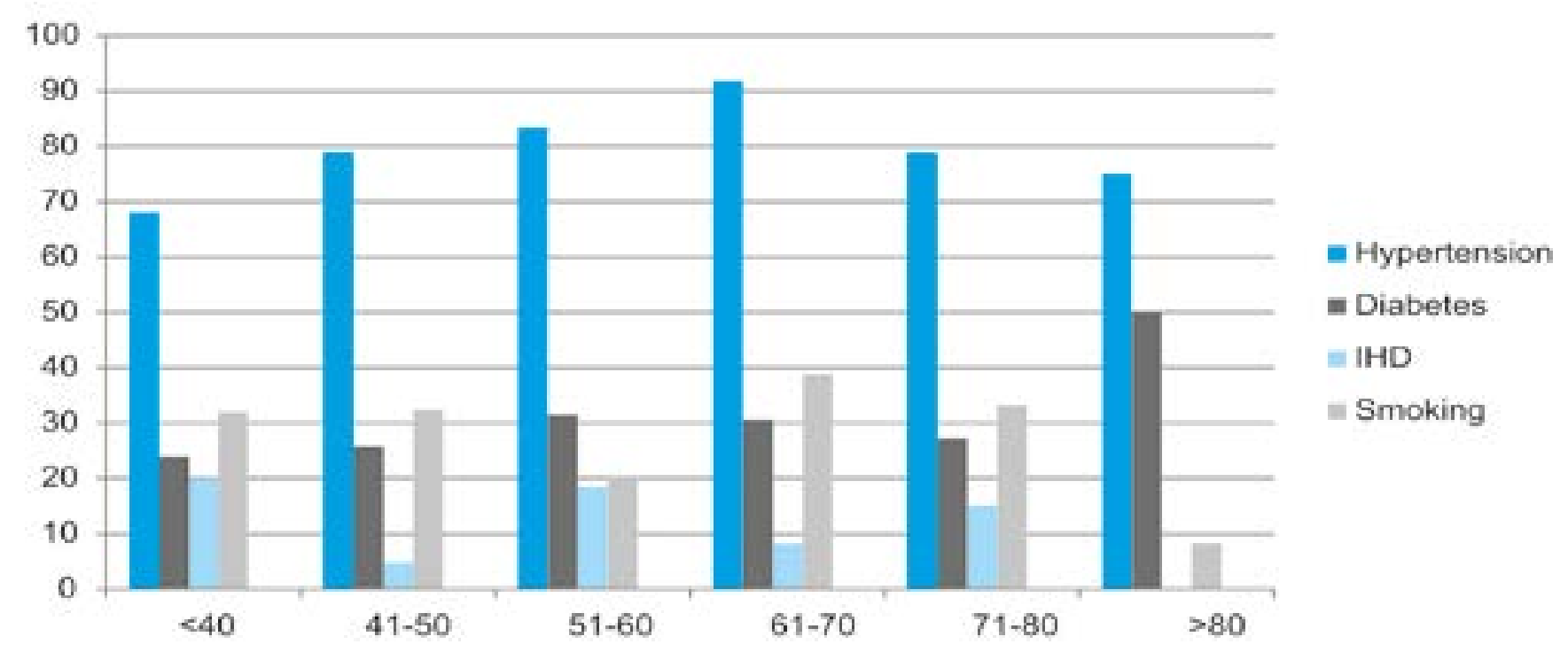

Figure-2. Risk Factors percentage within the Age groups 
Except diabetes, there was no significant relationship between mortality and risk factors, as DM and mortality was associated at $p=0.016$. Most of the hospitalized patients were with altered state of consciousness -ALOC (68.9\%), and right sided weakness (45.1\%) (Figure 3).

Mortality rate had reverse relationship between facial palsy $(p=0.014)$ and dysarthria $(p=0.006)$. Only 13 patients who had facial palsy and 4 with dysarthria died. Mortality rate also had reverse association with level of consciousness $(\mathrm{P}<0.0001)$ (Table II).

Patients who were more conscious were among the survivals (Figure 4) Duration of stay in the most of patients was 1-3 three for both types of strokes.

\section{DISCUSSION}

Stroke is a major cause of morbidity and mortality with disability and social dependence. Our hospital is a tertiary care referral centre for stroke patients, well known for neurology and neuro surgery. We get patients from all across Pakistan, specially for neuro-surgery, which results in heavy patient load of such patients. Findings reported by other studies in Iran and the USA, the mean age of patients with stroke was $68.3 .^{2}$ Khan JA et al and Vohra et al reported that $26 \% \& 34 \%$ of their patients were under the age of $45 \& 50$ years, respectively. ${ }^{3}{ }^{4}$ Syed et al reported a frequency of $28 \%$ of young stroke under age of 55 years. ${ }^{5}$ In our study most of the patients were between 40 to 70 years which were in the range of $20 \%$ to $26.4 \%$ with a total of $70.4 \%$. Above 70 and below 40 years, there were $19.1 \%$ \& $10.6 \%$, respectively. Bhojo A. Khealani ${ }^{3}$ mention the mean age of stroke varied from 52 to 66 years and the male to female ratio was 1.5. Regarding the sex pattern of stroke studies conducted in Iran, women were more likely to experience stroke than men, but some studies have documented that $55 \%$ of the patients with stroke are male in the USA. ${ }^{12}$

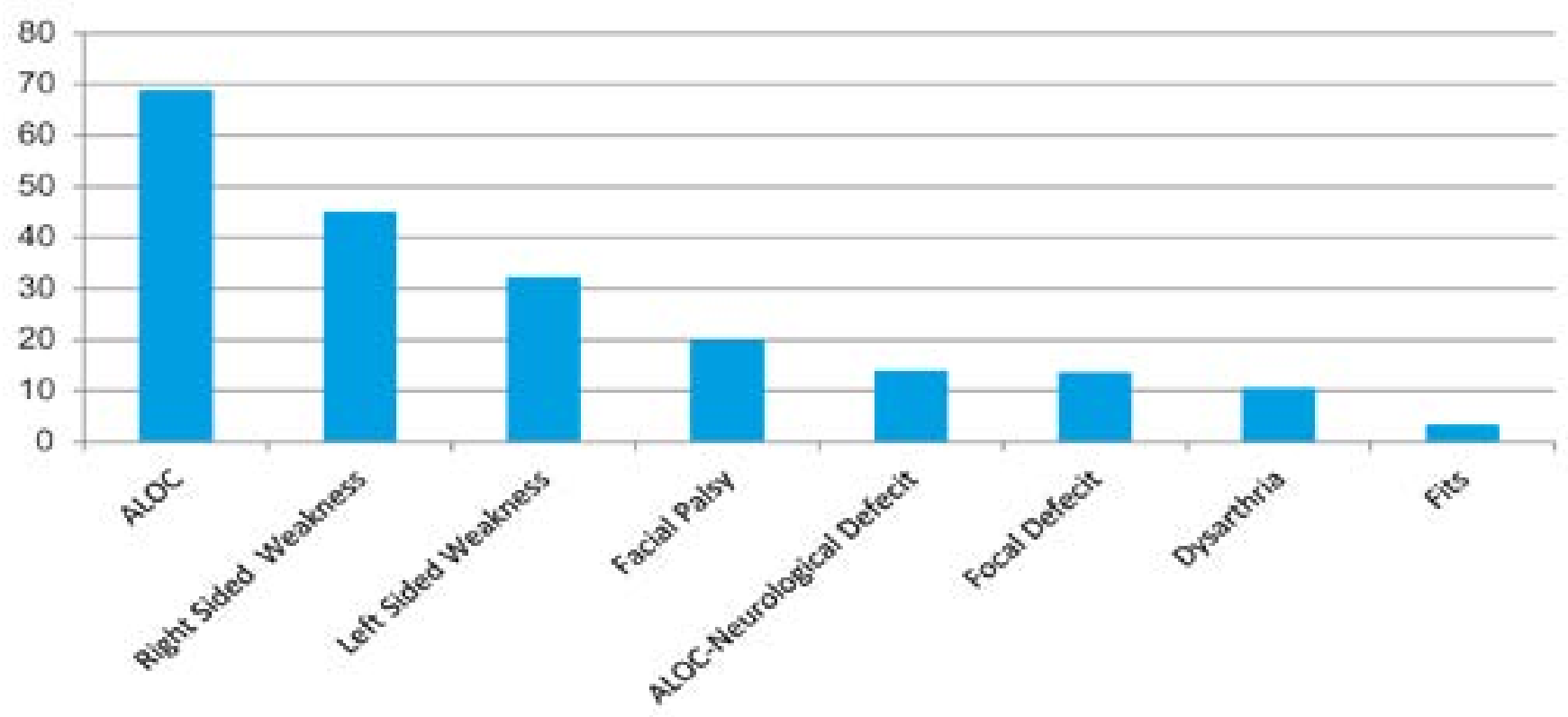

Figure-3. Neurological Signs

\begin{tabular}{|c|c|c|c|c|}
\hline & Prevalence (\%) & Mortality (\%) & OR (95\% Confidence Interval & P values \\
\hline Conscious & $41(17.4 \%)$ & $0(0 \%)$ & $-2.18(1.86-2.5)$ & $<0.001$ \\
\hline Confuse & $53(22.6 \%)$ & $4(4 \%)$ & $0.16(0.06-0.42)$ & $<0.001$ \\
\hline Stupor & $113(48.1 \%)$ & $72(72 \%)$ & $2.6(1.86-3.75)$ & $<0.001$ \\
\hline Comatose & $28(11.9 \%)$ & $24(24 \%)$ & $2.2(1.76-2.80)$ & $<0.001$ \\
\hline
\end{tabular}




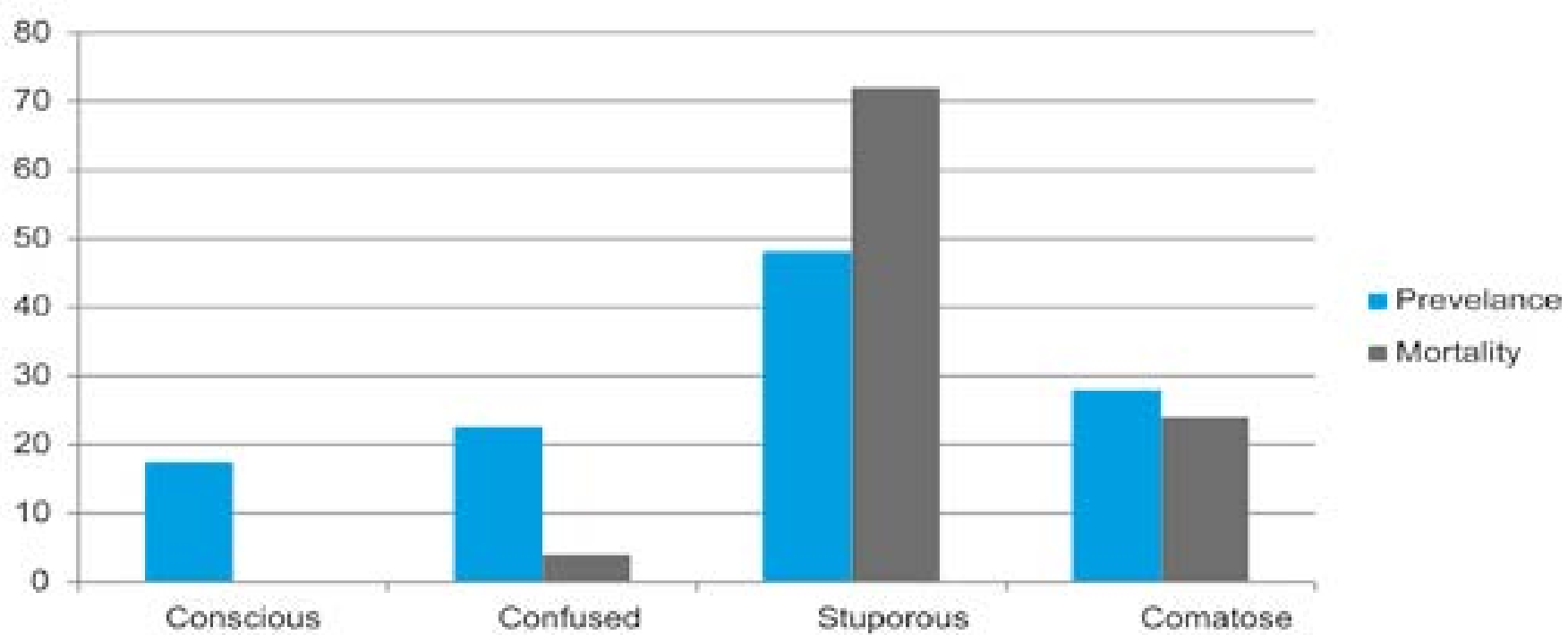

Figure-4. Level of Consciousness

These figures were different from our study with males affected were (54\%) as compared to the females $(46 \%) .{ }^{13}$ The reason for this difference from studies in ASIA could be geographic, education level or availability, but it also appears similar to the study in USA.

Babak Daneshfard ${ }^{1}$ mentioned proportion of the patients with IS and HS in their studies were $88.2 \%$ \& $11.8 \%$. In our study cases of HS were more. The possible reason could be poor awareness and uncontrolled most common risk factors of stroke, the hypertension, Diabetes and Dyslipidemia.

In our study group, $42.6 \%$ of all the patients died during their stay in the hospital. Mortality was more with the hemorrhagic $21.7 \%$ than ischemic $17.9 \%$ and nearly equal in both genders males (22.6\%) and females (20\%). The mortality of different types of stroke was similar to 28 days mortality of other studies conducted in Iran and the USA. ${ }^{14}$ It was comparable to the study by Bhoja A Khealani et $\mathrm{al}^{3}$ which was $11-30 \%$ and higher than Babak Daneshfard et $\mathrm{al}^{1}(12.1 \%)$. Mortality rate also had reverse association with level of consciousness as $68.9 \%$ of our patients were comatose on presentation. It was similarly documented by Ahmed et al ${ }^{15}$ in their retrospective series of 221 patients with $\mathrm{ICH}$ reported that intraventricular extension, low GCS and systolic BP $>180 \mathrm{mmHg}$ predict inpatient mortality.

Different risk factors were also compared. Hypertension, lack of exercise, Diabetes Mellitus, Smoking, dyslipidemia and obesity were the most common risk factors. There values were $82 \%, 53 \%, 29 \%, 29 \%, 13 \%$ and $11 \%$ respectively. Hypertension was the most common factor. Similarly, other studies have documented hypertension as the most prevalent risk factor for stroke. Similar documentation was available from India ${ }^{7}$, where different risk factors were observed in a review articles, and hypertension was one of the major factor. Difference may be due to the documentation in literature that in our population more than $70 \%$ of people with hypertension were unaware of their condition, and only $3 \%$ had adequately controlled blood pressures. ${ }^{3}$

Diabetes was the second most important risk factor in our study, present in $29 \%$ of patients. These findings were different from the AlRubeaan et $\mathrm{al}^{16}$ where only ischemic stroke was studied. Total prevalence here was only $4.42 \%$ and 62,s was an important risk factor, and more type 2 patients were affected. Hyperlipidemia, Smoking and hypertension were other important risk factors. Our findings showed that right \& left side weakness, facial palsy and dysarthria are the most common neurological signs which are 
in agreement with previous findings.

One important finding was the mortality according to conscious level in our study. Most patients were in stupor, followed by confusional state, conscious and finally in coma. Mortality was highest in stupor patients, followed by comatosed very few were in the confused state. Mortality was negligible in conscious patients. It was different from the what was documented by Daneshfard et $\mathrm{al}^{1}$ and Ekeh et $\mathrm{al}^{17}$ in their studies. Although mortality was high in comatosed patients and despite being less in number, there were good number of patients in the conscious patients with mortality. Mortality increased from confusion to stupor and finally coma. The difference in our study may be due to the reason that our hospital is a tertiary care hospital. More serious patients arrive here. They are more complicated and hence having more chances of mortality.

\section{CONCLUSION}

Burden of stroke is high in Pakistan. The mean age of patients with stroke is less. Hypertension and other risk factors like diabetes, dyslipidemia, smoking etc. are highly prevalent in the country in which hypertension is the most common. Although Ischemic strokes are more common than hemorrhagic strokes, the relative mortality of intra-cerebral hemorrhage is higher. There is an urgent need of improvement in creating awareness and education in general public regarding stroke and to control its modifiable risk factors to improve quality of life.

\section{LIMITATIONS}

There are several limitations in our study. First is that our hospital is a tertiary care institute, catering specialty patients. It may not be a true reflection of population. Second is that there are missing data in our system, which is done all manually, and difficult to retrieve. Patient record may be missing or they may not be recorded correctly. There is also poor co-ordination between different departments which may have contributed in our findings. We therefore suggest a relatively larger registry, just like for Dengue patients established at government level, to predict true figures and plan better for risk reduction.

Copyright(c) 15 May, 2016.

\section{REFERENCES}

1. Daneshfard B, Izadi S, Shariat A, Toudaji MA, Beyzavi Z, Niknam L. Epidemiology of stroke in Shiraz, Iran. Iran J Neurol. 2015 Jul 6;14(3):158-63.

2. Appelros P, Stegmayr B, Terént A. Sex differences in stroke epidemiology: a systematic review. Stroke J Cereb Circ. 2009 Apr;40(4):1082-90.

3. Khealani BA, Hameed B, Mapari UU. Stroke in Pakistan. JPMA J Pak Med Assoc. 2008 Jul;58(7):400-3.

4. Vohra EA, Ahmed WU, Ali M. Aetiology and prognostic factors of patients admitted for stroke. JPMA J Pak Med Assoc. 2000 Jul;50(7):234-6.

5. Syed NA, Khealani BA, Ali S, Hasan A, Akhtar N, Brohi $H$, et al. Ischemic stroke subtypes in Pakistan: the Aga Khan University Stroke Data Bank. JPMA J Pak Med Assoc. 2003 Dec;53(12):584-8.

6. Yusuf S, Hawken S, Ounpuu S, Dans T, Avezum A, Lanas $F$, et al. Effect of potentially modifiable risk factors associated with myocardial infarction in $\mathbf{5 2}$ countries (the INTERHEART study): case-control study. Lancet Lond Engl. 2004 Sep 11;364(9438):93752.

7. Banerjee TK, Das SK. Fifty years of stroke researches in India. Ann Indian Acad Neurol. 2016 Mar;19(1):1-8.

8. Muscari A, Faccioli L, Ghinelli M, Napoli C, Pirazzoli E, Puddu GM, et al. Hypertension and Other Determinants of White Matter Lesions in Stroke Patients. J Clin Hypertens Greenwich Conn. 2016 Jan 28;

9. Estol CJ, Rojas MME y. Stroke in Argentina. Int $\mathrm{J}$ Stroke. 2010 Feb 1;5(1):35-9.

10. Murray V, Norrving B, Sandercock $P$ a. G, Terént A, Wardlaw JM, Wester P. The molecular basis of thrombolysis and its clinical application in stroke. $\mathrm{J}$ Intern Med. 2010 Feb;267(2):191-208.

11. Khan M, Ahmed B, Ahmed M, Najeeb M, Raza E, Khan F, et al. Functional, cognitive and psychological outcomes, and recurrent vascular events in Pakistani stroke survivors: a cross sectional study. BMC Res Notes. 2012;5:89.

12. Johnson M, Bakas T. A review of barriers to thrombolytic therapy: implications for nursing care in the emergency department. J Neurosci Nurs J Am Assoc Neurosci Nurses. 2010 Apr;42(2):88-94.

13. EBSCOhost | 85740991 | Effect of stress hyper- 
glycemia (sh) on mortality rate among acute ischemic stroke (is) patients. [Internet]. [cited $2016 \mathrm{Mar}$ 29]. Available from: http://web.b.ebscohost.com/ abstract? direct $=$ true \& profile $=$ ehost $\&$ scope $=$ site $\&$ authtype $=$ crawler \&jrnl $=16815491 \& A N=85740991 \& \mathrm{~h}$ = CuySNSZYvo32kDLW5E\%2b1BZYLd1At0g6GmPsj1NrwCahiymtM\%2f8gctjQvRDM8kDjnZRSHb44vOtPp8hhQ6i\%2f4Fg\%3d\%3d\&crl=c\&resultNs=AdminWebAuth\&resultLocal = ErrCrINotAuth\&crlhashurl=login.aspx\%3fdirect\%3dtrue\%26profile\%3dehost\%26scope\%3dsite\%26authtype\%3dcrawler\%26jrnl\%3d16815491\%26AN\%3d85740991.

14. Hosseini AA, Sobhani-Rad D, Ghandehari K, Benamer HTS. Frequency and clinical patterns of stroke in Iran - Systematic and critical review. BMC Neurol. 2010;10:72.
15. Ahmed R, Shakir AH, Moizuddin SS, Haleem A, Ali S, Durrani K, et al. Predictors of in-hospital mortality for intracerebral hemorrhage: a hospital-based study in Pakistani adults. $\mathrm{J}$ Stroke Cerebrovasc Dis Off $\mathrm{J}$ Natl Stroke Assoc. 2001 Jun;10(3):122-7.

16. Al-Rubeaan $\mathrm{K}, \mathrm{Al}-$ Hussain $\mathrm{F}$, Youssef AM, Subhani $\mathrm{SN}$, Al-Sharqawi AH, Ibrahim HM. Ischemic Stroke and Its Risk Factors in a Registry-Based Large Cross-Sectional Diabetic Cohort in a Country Facing a Diabetes Epidemic. J Diabetes Res. 2016;2016:4132589.

17. Ekeh B, Ogunniyi A, Isamade E, Ekrikpo U. Stroke mortality and its predictors in a Nigerian teaching hospital. Afr Health Sci. 2015 Mar;15(1):74-81.

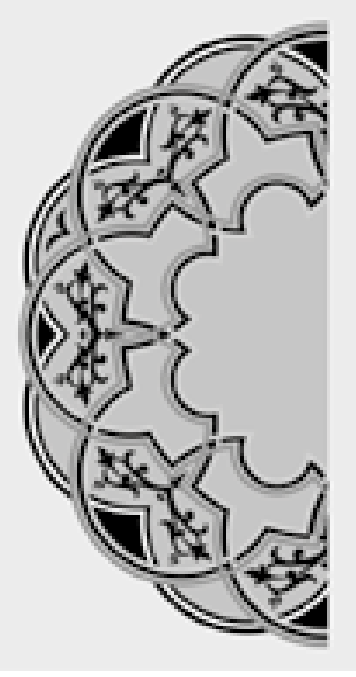

\title{
"The capacity to learn is a gift; The ability to learn is a skill; The willingness to learn is a choice."
}

\author{
Brian Herbert
}

\section{AUTHORSHIP AND CONTRIBUTION DECLARATION}

\begin{abstract}
Sr. \#
1

Author-s Full Name

M. Imran Hasan Khan
\end{abstract}

2 Asim Hameed

3 Zohaib Abbas Khan

4 Sana Fatima
Contribution to the paper

Research idea, SUpervision, Review of Literature and Final review of the manuscript

Data Collection, Write up

Statistical Analtysis, Result calculation and results writing. Data collection and Entry in the SPSS
Author $=$ s Signature

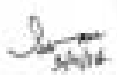

Anot ate

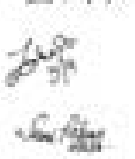

